\title{
Do more overweight patients at admission lose weight during hospitalization
}

\author{
Vânia Aparecida Leandro-Merhi ${ }^{1,2}$, Milena Vieira Teles ${ }^{2}$, José Luis Aquino² ${ }^{2}$ José \\ Alexandre Mendonça ${ }^{2}$, and Elisa Teixeira Mendes ${ }^{2}$ \\ ${ }^{1}$ Pontifícia Universidade Católica de Campinas \\ ${ }^{2}$ PUC-Campinas
}

June 30, 2020

\begin{abstract}
Objective: Investigate in-patients weight loss during hospital stay. Methods: In a retrospective study carried out with 170 in-patients, weight loss during hospitalization and its relationship with the type of disease, diet therapy, subjective global assessment (SGA), nutritional risk screening (NRS), anthropometry and hospitalization time (HT) were investigated. The Chi-square test, the Mann-Whitney and the univariate and multiple Cox regression analysis were used. Results: During hospitalization $41.18 \%$ patients experienced weight loss. Patients who were overweight experienced a higher rate of weight loss while in the ward $(45.7 \%$ of patients; $\mathrm{p}=0.0179)$. Patients who were overweight, were twice as likely to lose weight during hospitalization, when compared with those who were already underweight $(\mathrm{p}=0.0339 ; \mathrm{HR}=2.312$; CI \% $=1.066 ; 5.018)$. The age, gender, disease, diet prescribed during hospitalization, SGA, NRS, anthropometry and fasting time were not considered risk factors associated with weight loss. Conclusion: There was no influence of the dietary therapy type on weight loss. Only those patients who were overweight according to BMI were more associated to lose weight during hospitalization.
\end{abstract}

\section{Introduction}

Already widely recognized in the relevant literature, the occurrence of malnutrition in hospitalized patients was observed in previous publications, under different clinical conditions, and has been evaluated and diagnosed with different nutritional screening instruments ${ }^{1,2,3}$. In a recent study, the malnutrition observed in hospitalized cancer patients, points to the adoption of procedures and quality control in the use of nutritional interventions ${ }^{3}$. With regard to the weight loss observed in hospitalized patients, recent studies show that weight loss may represent a relevant prognostic factor in this population ${ }^{4}$. In an investigation ${ }^{5}$ on nutritional parameters associated with length of stay, patients who had a hospital length of stay of three days or more, were the ones with most death cases, low body mass index, nutritional risk and unintentional weight loss greater than or equal to $5 \%$, both before and after hospital admission. Some findings show that the nutritional depletion by subjective global assessment and weight loss was associated with prolonged hospital stay, regardless of other risk factors ${ }^{6}$. In view of these considerations, this study investigated in-patients weight loss during hospital stay. 


\section{Method}

A retrospective investigation was developed with hospitalized patients after approval by the institution's ethics and research committee (CAEE Opinion No. 75798017.0.0000.5481). Data was collected from medical records of 170 adult and elderly in-patients, including patients aged 20 years or older, without terminal illness and with complete record of all information on weight loss, weight evolution, nutritional status and type of ward dietary therapy prescribed. Patients hospitalized for clinical investigation and exams were excluded from the study.

The evolution of body weight during the hospital stay period and the body mass index (BMI) were evaluated, according to the cutoff points established for adults and the elderly ${ }^{7,8}$. Arm circumference (AC), triceps skin fold (TSF), arm muscle circumference (AMC) ${ }^{9,10}$ and calf circumference (CC) ${ }^{11}$ were analyzed according to standardized procedures ${ }^{9,10}$.

Nutritional risk was assessed by the Nutritional Risk Screening (NRS) and nutritional status by the subjective global assessment (SGA), right at the beginning of hospitalization, as recommended by Kondrup, et al., (2003) 12 and Detsky, et al ., (1994) ${ }^{13}$; respectively. According to the NRS, patients were considered at nutritional risk or without nutritional risk ${ }^{12}$. Patients were classified by SGA as well-nourished, mildly, moderately or severely malnourished. Subsequently, patients classified as mildly, moderately or severely malnourished, were considered to be malnourished.

The type of dietary therapy prescribed during hospitalization was reviewed. The prescribed diets were classified as general diet(without changes in food consistency, that is, with food in solid form); bland diet (with well-cooked and non-spicy foods); liquid diet (composed of liquefied foods); enteral or parenteral diet and oral fasting. The fasting period varied according to the patient's clinical evolution.

\section{Statistical Analysis}

For categorical and continuous variables, a descriptive analysis of the data was performed. The Chi-square and Mann-Whitney tests were used to compare proportions and continuous or ordered measures, between two groups, respectively. Cox univariate and multiple regression analysis was used to analyze the risk factors associated with weight loss during hospitalization. The level of significance was set at $5 \%(\mathrm{p}<0.05)^{14,15,16}$.

Results

In this investigation $(\mathrm{n}=170$ patients), $62.94 \%(\mathrm{n}=107)$ were male and $37.06 \%(\mathrm{n}=63)$ were female. A total of $30.59 \%(\mathrm{n}=52)$ patients with vascular diseases were found; $27.65 \%(\mathrm{n}=47)$ with digestive neoplasms; $18.24 \%$ $(\mathrm{n}=31)$ with digestive tract diseases (DTD); $11.18 \%(\mathrm{n}=19)$ with head and neck neoplasms; $6.47 \%(\mathrm{n}=11)$ with kidney and urological diseases and $5.88 \%(\mathrm{n}=10)$ with lung diseases. A nutritional risk by NRS was detected in $39.41 \%(\mathrm{n}=67)$ patients and malnutrition by SGA in $24.12 \%(\mathrm{n}=41)$ patients.

By anthropometry, 21.76\% underweight patients were observed by BMI. It was observed that 37.65\%, $20 \%$ and $41.18 \%$ of patients were below or equal to the $15^{\text {th }}$ percentile (P15) for AC, TSF and AMC, respectively.

It was also found that $41.18 \%(\mathrm{n}=70)$ of the patients experienced weight loss during hospitalization and $75.88 \%$ ( $\mathrm{n}=129$ ) stayed in hospital for a period longer than 7 days. The mean age was $60.7 \pm 13.6$ years and the length of hospital stay was $14.5 \pm 10.2$ days. In the dietary prescription upon admission, $33.53 \%(\mathrm{n}=57)$ of the patients received a general diet; $24.71 \%(\mathrm{n}=42)$ a bland diet; $12.35 \%(\mathrm{n}=21)$ enteral or parenteral diet, $6.47 \%(\mathrm{n}=11)$ liquid diet and $22.94 \%(\mathrm{n}=39)$ stayed with an oral fasting prescription.

In this study, a comparison was made of all the variables studied, between patients with and without weight loss. There was a statistically significant difference, only for the type of disease and the BMI classification. Patients with DTD (27.1\% with weight loss) and digestive neoplasia (31.4\% with weight loss) showed greater weight loss during hospitalization, with a statistically significant difference $(\mathrm{p}=0.0334)$. Among patients who were overweight by their BMI, $45.7 \%(\mathrm{n}=32)$ of them exhibited a higher percentage of weight loss during hospitalization $(\mathrm{p}=0.0179)$. 
There was no statistically significant difference in the comparison between patients with and without weight loss, in the gender, age, length of hospital stay, fasting time, SGA, NRS, AC, TSF, AMC, CC and type of dietary therapy.

It was found that those patients who were overweight by BMI, were twice as likely to lose weight during hospitalization, when compared with those who were underweight on admission $(p=0.0339 ; H R=2,312 ; C I$ $\%=1,066 ; 5,018)$. The other variables studied such as age, gender, disease type, type of diet prescribed during hospitalization, SGA, NRS, AC, TSF, AMC, CC and time of fasting were not considered; risk factors associated with weight loss when analyzed by the Cox regression analysis (Table 1).

\section{Discussion}

This study is a pilot investigation into the occurrence of weight loss during hospitalization. The strong point of this study is the investigation of weight loss measured during the hospitalization period, performed directly by the professionals of the hospital health team.

When comparing the two groups of patients, those who lost weight and those who did not lose weight during hospitalization; no association was found between the nutritional variables investigated, the length of hospital stay and the type of diet. At the beginning of this investigation, the hypothesis was that patients who lost weight could be those with a malnutrition condition already installed or those receiving diets of liquid consistency, because in these conditions, patients, in general, could present a deterioration of their nutritional status or a reduction in energy consumption. It was interesting to note that patients with DTD and digestive neoplasms, as well as those who were overweight by BMI, were those who experienced the greatest weight loss during the course of hospitalization. It was observed that only high BMI influenced the weight loss process during hospitalization, since overweight patients were those who were twice as likely to lose weight during hospitalization. Some studies in the relevant literature ${ }^{4,17}$ have shown the importance and the need to investigate weight loss and its relationship with in-patients ${ }^{18}$ and mortality ${ }^{4,17}$. A study by Barazzoni et al, $2019^{4}$, investigated the impact of recent self-reported weight loss on hospital mortality, showing that self-reported weight loss could represent a relevant prognostic factor in hospitalized patients. Unlike that article, our study investigated the weight loss that occurred in the hospital setting, throughout the hospitalization period, pointing out that only the classification by BMI was significant and associated with weight loss. Overweight patients were at increased risk of losing weight during hospital stay. In the study by van der Schueren et al , 2018 ${ }^{17}$, patients who presented critical weight loss, presented higher mortality in one year, when compared with patients without critical weight loss. In that same study ${ }^{17}$; it was observed that the fat free mass index played an important role in this association, since the authors reported that mortality rates were lower in patients with normal weight and with normal fat free mass index. Another study ${ }^{18}$ that evaluated the association between admission weight, weight loss and length of stay of patients with pancreatic necrosis, pointed out that those patients had a considerable risk of malnutrition and that a BMI above $25 \mathrm{~kg} / \mathrm{m} 2$ predicts greater weight loss and longer hospital stay.

\section{Conclusion}

There was no influence of the type of dietary therapy on weight loss. Only those patients who were overweight by BMI were more associated to lose weight during hospitalization.

\section{References}

1. Mogensen KM, Bouma S, Haney A, Vanek VW, Malone A, Quraishi SA, Guenter P. (2018). Hospital Nutrition Assessment Practice 2016 Survey.Nutr Clin Pract. Oct 33(5):711-717. doi: 10.1002/ncp.10179. Epub 2018 Aug 8. 
2. Takaoka A, Sasaki M, Nakanishi N, Kurihara M, Ohi A, Bamba S, Andoh A. (2017). Nutritional Screening and Clinical Outcome in Hospitalized Patients with Crohn's Disease.Ann Nutr Metab. 71(3-4):266-272. doi: 10.1159/000485637. Epub 2017 Dec 14.

3. Li Z, Chen W, Li H, Zhao B; Chinese Oncology Nutrition Survey Group. (2018). Nutrition support in hospitalized cancer patients with malnutrition in China.Asia Pac J Clin Nutr. 27(6):1216-1224. doi: 10.6133/apjcn.201811_27(6).0007.

4. Barazzoni R, Sulz I, Schindler K, Bischoff SC, Gortan Cappellari G, Hiesmayr M; nutritionDay Research Group. (2019). A negative impact of recent weight loss on in-hospital mortality is not modified by overweight and obesity. Clin Nutr. Nov 12. pii: S0261-5614(19)33134-6. doi: 10.1016/j.clnu.2019.11.007. [Epub ahead of print]

5. Caccialanza R, Klersy C, Cereda E, Cameletti B, Bonoldi A, Bonardi C, Marinelli M, Dionigi P. (2010). Nutritional parameters associated with prolonged hospital stay among ambulatory adult patients. Canadian Medical Association Journal 182(17):1843-1849.

6. Allard JP, Keller H, Jeejeebhoy KN, Laporte M, Duerksen DR, Gramlich L, Payette H, Bernier P, Davidson B, Teterina A, Lou W. (2016). Decline in nutritional status is associated with prolonged length of stay in hospitalized patients admitted for 7 days or more: A prospective cohort study. Clin Nutr. Feb; 35(1):14452. doi: 10.1016/j.clnu.2015.01.009. Epub 2015 Jan 21.

7. World Health Organization (WHO). (1998). Obesity: Preventing and managing the global epidemic Report of a WHO Consultation on obesity. Geneva: WHO.

8. Lipschitz DA. (1994). Screening for nutritional status in the elderly. Prim Care 22(1):55-67.

9. Frisancho AR. (1990). Anthropometric standards for the assessment of growth and nutritional status. Michigan: The University of Michigan Press; 189p.

10. Burr ML, Phillips MK. (1984). Anthropometric norms in the elderly.Br Journal of Nutrition 51:165-9.

11. World Health Organization.(1995). Physical status: the use and interpretation of anthropometry: report of a WHO Expert Committee. Geneva: WHO.

12. Kondrup J, Allison SP, Elia M, Vellas B, Plauth M. (2003). European Society for Clinical Nutrition and Metabolism (ESPEN) Guidelines for nutrition screening 2002. Clin Nutr. 22(4):415- 421.

13. Detsky AS, McLaughlin JR, Baker JP, Johnston N, Whittaker S, Mendelson RA, Jeejeebhoy KN. (1987).What is subjective global assessment of nutritional status? JPEN J Parenter Enteral Nutr 11:8-13.

14. Conover WJ. (1971). Practical non parametric statistics .John Wiley \& Sons Inc. Nova Iorque.

15. Tabachnick BG, Fidell LS. (2001). Using Multivariate Statistics . Needham Heights, MA: Allyn\&Bacon, $4^{\text {th }}$ ed.

16. SAS System for Windows (Statistical Analysis System): versão9.4. Cary, NC: SAS Institute Inc, 20022012 .

17. de van der Schueren MAE, de Smoker M, Leistra E, Kruizenga HM. (2018). The association of weight loss with one-year mortality in hospital patients, stratified by BMI and FFMI subgroups. Clin Nutr. 2018 Oct;37(5):1518-1525. doi: 10.1016/j.clnu.2017.08.024. Epub 2017 Aug 31.

18. Rysgaard S, Rasmussen D, Novovic S, Schmidt PN, Gluud LL. (2017). Effect of overweight and obesity on weight loss and length of stay in patients with walled-off pancreatic necrosis.Nutrition. 2017 Jun;38:109112. doi: 10.1016/j.nut.2017.01.006. Epub 2017 Feb 3.

\section{Hosted file}


Table 1 to JECP.docx available at https://authorea.com/users/337862/articles/464420-do-moreoverweight-patients-at-admission-lose-weight-during-hospitalization 